\title{
An Explanatory Case Study on Cloud Computing Applications in the Built
}

\section{Environment}

\author{
Heap-Yih Chong ${ }^{1,2 *}$, John Son Wong ${ }^{1}$ and Xiangyu Wang ${ }^{2,3}$ \\ ${ }^{1}$ Faculty of Engineering \& Science, Universiti Tunku Abdul Rahman, Malaysia. \\ ${ }^{2}$ Australasian Joint Research Centre for Building Information Modelling (BIM), School of \\ Built Environment, Curtin University, Australia. \\ ${ }^{3}$ Department of Housing and Interior Design, Kyung Hee University, Seoul, Korea.
}

\begin{abstract}
Fragmentation of practices is one of the key issues in the built environment. However, with advances in Information and Communication Technology (ICT), particularly cloud computing, the fragmentation of working practices can be potentially overcome. The technology could enhance communication and information flow in various stages along a project life cycle. Due to the increasing demands and the newly developed cloud computing applications, it is critical to review and identify the appropriate cloud computing applications in the built environment. A total of forty two cloud computing applications consisting of general cloud applications, Building Information Modelling (BIM), and project management cloud applications were selected and critically reviewed. A decision-making model was also developed to assist parties in selecting a suitable application. The explanatory case study has discovered numerous possible cloud computing applications in various disciplines, for example, Google Apps, Autodesk BIM 360, and Viewpoint are the applications with the most features. The findings contribute to creating a certain awareness and insight to reduce the fragmented working practices in the built environment.
\end{abstract}

\footnotetext{
*Corresponding author.

E-mail address: heapyih.chong@curtin .edu.au or heapyihchong@gmail.com (H.Y. Chong).
} 
Keywords: Cloud computing; BIM; project management; critical review; information management

\section{Introduction}

Fragmented work practices are a common scenario due to many individual participants in a project, each having their own objectives and goals [7]. This situation becomes worse when the project life cycle involves many stages, from conception to construction to demolition [6]. Fragmentation will lead to poor communication and decreased efficiency in the industry [14].

The highly fragmented situation has to be overcome in order to manage the project life cycle more efficiently. Application of information and communication technology (ICT) is able to manage the project risks and enhance the coordination [32]. Cloud computing is also known as 'shared computing' in the past decades. It recognizes as an advanced computing technology where software and hardware are delivered as a platform for collaborative service through the network. In recent years, cloud computing technology has begun to become even more popular as to support processing and interchanging of voluminous data, modular interactivity and inter-applications communications. Moreover, the easy access to and availability of the internet have also promote the concept of sharing in cloud computing.

Many applications can be delivered through cloud computing, such as project management, database management, and the recent emerging technology called Building Information Modelling (BIM). A BIM project is able to create more collaboration within project teams, improved profitability, reduced costs, better time management and improved customer/client relationships [3]. Previous studies on BIM have been focused on the implementation and the adoption frameworks of BIM [2,12,25,29]. Some researchers have suggested that BIM must instead be upgraded with new technologies such as cloud computing [24] and augmented reality [19, 30], which are able to enhance design 
coordination or even facilities management [31]. It can improve the project in cost, value and carbon performance by exchanging information in the cloud [21]. This technology is going to play an integral part of future BIMs [8]. Some attempts were carried out, especially on the pilot frameworks of various aspects of management $[7,13]$.

Therefore, due to the increasing demands and the increasing newly developed cloud computing applications that are constantly being designed in the market, there is a need to conduct an explanatory case study research to review and identify the appropriate cloud computing applications in the built environment. Therefore, the research objectives are (a) to critically review and compare current cloud computing applications and related tools and platforms in the built environment and (b) to develop a decision-making model for the selection of a cloud computing application in the built environment.

This research will assist the parties involved to make informed decisions in selecting suitable applications for their projects, and subsequently the process of project delivery could be tremendously improved through a more efficient and collaborative manner of managing the information flow in the project.

\section{Cloud Computing}

Cloud computing is a shared computing technology where software and hardware are delivered as a service through the real-time network, for instance, the internet. The most common definition of cloud computing has been defined by National Institute of Standard and Technology (NIST) [18] as “a model for enabling ubiquitous, convenient, on-demand network access to a shared pool of configurable computing resources (e.g., networks, servers, storage, applications, and services) that can be rapidly provisioned and released with minimal management effort or service provider interaction”. 
Generally, cloud computing services can be categorized into three main types of services: Infrastructure as a Service, Platform as a Service and Software as a Service. These services can then be accessed through a cloud client which could be a web browser, mobile app, and so on.

Infrastructure as a Service (IaaS) is a service where the hardware is hosted by the service provider and the customer only pays for the use of the hardware [34]. The IaaS can be further divided into Software Infrastructure as a Service (SIaaS) and Hardware Infrastructure as a Service (HIaaS). SIaaS describes as a stand-alone cloud service that only supports a specific application, but not the whole application software; whereas HIaaS is a virtual or physical hardware resource that provides a service, for example, Microsoft SQL [23]. The hardware provided can be described as an infrastructure of servers that can provide services such as storage, computing ability, virtualization, etc. The main advantage of this form of service is that it dramatically decreases the hardware cost for users, as only the minimum requirements for hardware will be required. This type of service is defined as the capability provided to the user to acquire processing, storage, networks and any other applications available on the infrastructure for rent [17]. It is also stated that the user will not be able to control the infrastructure but will be able to control the applications used through the infrastructure.

There are several notable components that IaaS services should also include. These components serve as a utility computing service and billing model, automation of administrative tasks, dynamic scaling, desktop virtualization, policy-based services and internet connectivity [4]. Currently, there are several notable providers, such as Amazon's EC2, GoGrid’s Cloud Servers and Joyent [28].

On the other hand, compared with the IaaS model, where only hardware is provided through the cloud, the Platform as a Service (PaaS) model is a model where hardware and a certain amount of application software is provided together as a set to the user, as described 
by Bhardwaj [4], who also observe that PaaS is an application development and deployment application service provided to the user over the internet. PaaS is a development environment which is supplied as a service. PaaS is reported to act as a distribution platform server where the service provider provides services such as a developed environment, server platform and hardware resources, which are then used by the user to develop their own application and then supplied to other users across the internet [34]. The PaaS model gives the user the capability to deploy onto the cloud infrastructure or applications created by the user using programming languages, libraries, services and tools supported by the provider [17]. Some of the PaaS service providers listed by Zhang and Sultan, [28,34], are Google App Engine, Force.com, 800 APP, Microsoft’s Azure and Amazon web service.

The last of the cloud computing models is Software as a Service (SaaS). In this model, the user can use an applied software which is already provided by the service provider on their server [34]. Through this model, users can easily access the software through a browser and are charged on a per user or time used basis. It was asserted by Zhang et al. that this is the best way for a small business to take advantage of cloud computing technology as it is the simplest to use. The users do not get to manage or control the cloud infrastructure, network, servers, operating system, storage or even the application capabilities [17]. However, they may be able to control the user-specific application configuration settings. Some examples of applications provided through the SaaS model are productivity applications such as word processing, spreadsheets, etc. More complex programs such as those for Customer Relationship Management (CRM) and Enterprise-Resource Management (ERM) can also be provided through this model [28].

This service model of cloud computing typically hosts and manages applications which are then available to users through the web. However, this does not necessarily mean the service provider also provides PaaS or IaaS. Bhardwaj et al. mentioned in their paper that a 
SaaS provider may be running on other cloud providers for PaaS and IaaS, and is thus only providing the applications and software. Some SaaS service providers were also listed by Bhardwaj [4]. They are Oracle CRM on demand, Salesforce.com and Netsuite. Also, several SaaS providers such as Google Doc, Google Apps, Zoho Office, Yahoo mail, WebEx and Microsoft Office Live were reported [28,34].

Apart from that, it is worth to highlight some evolving technologies in relation to cloud computing $[10,15,20]$, namely, Server-based Computing or being described as "thinclient computing”, Hosted Client Computing, Web-based applications, and Rich Internet Application. These are relatively new technologies for the applications that would be hosted or run in the server or internet under different circumstances to ensure the connectivity and consistent functioning of the applications. Overall, the taxonomy of cloud computing is required to configure with a number of resources, namely, networks, servers, storage, applications, and services as illustrated in Figure 1 [9].

\subsection{The need for cloud computing}

Cloud computing has been increasingly popular in the past few years as it continues to prove that it gives substantial advantages to users who adopt this technology. These advantages have also been extensively discussed by many researchers and academicians around the world.

There are four main reasons why cloud computing is attracting more and more users [29]. The first reason is that it provides elasticity or flexibility, as users are free to request the amount of resources they need from the cloud, for example, the size of storage or servers. The next reason is that cloud computing is economical. This is because users only pay for what they use. For example, if the user only uses two servers they will only pay for those two. The third reason stated in the paper is that this technology is reliable because most of the 
services provided are fault-tolerant and are highly available. Finally, it is maintained by Tao et al. that cloud computing is more user-friendly and on-demand, as the services are tailored to individual requirements.

One of the main benefits is that cloud computing dramatically lowers the cost of entry for small firms who are trying to benefit from computer-intensive business analytics that were previously only accessible by large firms as they are extremely costly. Cloud computing has levelled the playing field for all parties. This lowered cost also opens up vast opportunities to third-world countries that may have been left behind in the IT revolution and have no access to these capabilities. These computing services can then be used to create endless possibilities of innovative IT applications, software and products. Some of the many promising start-ups, such as 37 Signals, Jungle Disk, Gigavox and SmugMug, are results of substantially lower IT investments compared with a few years ago; thus cloud computing can be a catalyst for increasing IT innovation [16].

Besides, cloud computing makes it easier for companies to scale their services, whether up or down, as the resources can be deployed very fast from the cloud. This in turn results in more efficient use of resources. For example, if a company suddenly requires more resources to meet higher demand they can quickly acquire the resources needed from the cloud, so avoiding potential loss of profit. On the other hand, if the company needs to scale down from low demand they can easily do this through the cloud without having to bear the additional operation or maintenance cost, unlike when physical hardware and software has been acquired by the company [16].

A case study was conducted on a UK-based SME with a workforce of 20 [28]. The company uses the Microsoft Azure cloud computing service and has commented that the service is reliable and efficient, although deployment to the cloud is slightly slower than to a 
local server. The Azure service also only costs the company about $20 \%$ of traditional hosting solutions.

Overall, the most cited benefits of cloud computing are agility, eliminates capital expenditure, reduced in-house IT staffing, lower monthly costs, enables adoption of latest technology, encourages standardization, simplifies sharing, reduces unused computing capacity and easy on-ramp to experiment with newer technologies [24]. Some of the new possible applications reported are [16]:

- Mobile interactive applications that respond to real-time information.

- Parallel batch processing to analyse terabytes of data in short periods of time.

- Business analytics to understand the customer, the supply chain, etc., that use large amounts of computer resources.

- Extensions of computer-intensive desktop applications that only show the processed data.

\subsection{Opportunities and Challenges in cloud computing}

Cloud computing technology and services have proven to provide many advantages for users. However, there are several disadvantages and risks to using cloud computing technology, with security being the major risk under discussion.

A recent survey of chief information officers and IT executives by the International Data Corporation rated security of cloud computing as the main concern, with an overwhelming majority of $75 \%$ of the respondents worrying about security [28]. With potentially private and confidential data that may jeopardise the user if stolen or leaked, security is a legitimate concern. 
Dorey and Leite [11] also highlighted that service providers' cloud computing, representing larger targets and storing larger amounts of data, may be more attractive to hackers or cyber-terrorists, who might get maximum information or cause maximum disruption of the service if these providers were targeted.

Another aspect of security that users are concerned about is the integrity or trustworthiness of third parties [11]. In many cases, cloud services are also provided by many third parties through other cloud providers, such as SaaS and PaaS providers through an IaaS provider. Thus users are concerned about the integrity, control and sustainability of the service provider.

The next disadvantage or risk that users, and especially large organizations, are concerned about is the loss of physical control of data that is put into the cloud, as mentioned by Marston [16], who observed that currently many service providers are unable to guarantee the location of a user's data on specified servers in a specified location. With this, the risk of lost or stolen data is greater as servers may be on the other side of the world where it is out of the control of the users.

Marston also stated the cloud can also be a trap [16]. As described in this study, this could happen when companies like Google force users into locked proprietary systems that will gradually cost more over time. Where large amounts of the users' data are already in the cloud, they may be forced to agree to pay the incremental charges, as it would be costly and time-consuming to move to another cloud or a private server.

Besides, the most cited risks of cloud computing are increased delegation to third parties, increased data security risks, reduced ability to limit physical access, reduced control over compliance, reduced control over disaster recovery, fear of increased overall costs, fear of reduced control over performance, fear of reduced availability, heightened integration 
concerns with in-house legacy systems, risk of vendor business failure and risk of vendor lock-in and lack of profitability [24].

The effective development and use of cloud computing should consider three main agendas, such as its initial adoption, technical development and governing policy. Ambrust and other researchers have developed ten obstacles and opportunities for the growth of cloud computing as per the agendas [1]. Table 1 shows the obstacles and opportunities for the development of cloud computing. On the other hand, policymakers have been advised to avoid cloud-specific legislations and localization mandates in using only local facilities, but to promote open standards and data interoperability, and also to embrace a global approach or international consensus standards to uphold cyber-security and protection of data [27].

\section{Research Approach: Explanatory Case Study}

An explanatory case study research usually compare with a set of variables to reach a specific outcome. This is a theoretical approach to present data bearing cause-effect relationships in identifying the suitable cloud computing applications in the built environment. This method can be described as a casual-process tracing approach, which it starts with an interest, and then to select and compare the cases/factors that lead to the research outcome [5].

\subsection{Selection and Critical review of cloud computing applications}

A critical review was conducted of the cloud computing applications and software selected. The selection was based on two criteria, namely, (a) the cloud computing applications must be cloud-enabled or have cloud functions, (b) the applications must be designed for the construction industry or for project management use. Subsequently, the search was mainly carried out based on Google search machine and recommendations from articles. 
The cloud applications were reviewed based on the information and reviews gathered from various sources in the internet. The main source of information for the applications was from the application websites and brochures. Tutorial and seminar videos of the applications were also viewed as one of the sources of information. Applications that were available for trial or free use were used and tested hands-on by the authors before the review was undertaken. Furthermore, reviews of the applications on other websites were also read for further information on them.

The applications were evaluated thoroughly to identify their key features. Other issues such as ease of use, user friendliness and resources for implementation were also reviewed.

\subsection{Comparison of cloud computing applications:}

The next stage of this research was to compare the various cloud applications. The comparison was done on the features available from the applications and separated into three distinct categories.

The first category is the general cloud applications available in the market. These applications are not specifically designed for use in the construction industry, but can be adapted and used for any industry, including the construction industry. Examples of this type of cloud application are Google Apps, Microsoft Office 365 and many more.

The second category of cloud application is cloud BIM applications. These applications are designed for the sole purpose of BIM, allowing users to share models through the cloud. The models may or may not be designed with the application and the application may just be a tool to allow sharing of the model.

The third and final category is for Project Management applications. These applications are specifically designed for project management and construction management. 


\subsection{Development of decision-making model}

The development of the decision-making model is to assist parties in the built environment, mainly the developer or project manager and contractor, to select an appropriate cloud computing application for their particular use. This is because these individuals are the backbone of the built environment and are in a position to influence and encourage the use of cloud applications. Furthermore, contractors were sub-divided into large and small sized firms to further evaluate the applications most suitable for them.

\section{Results}

\subsection{Objective 1: Critical review and comparative analysis}

A total of forty two cloud applications were critically reviewed and compared. The applications were separated into three distinctive categories for the ease of subsequent comparative analysis, namely general cloud applications, cloud BIM applications and cloud project management applications.

\section{General Cloud Applications}

The first cloud applications that parties in the construction industry can use and take advantage of are general cloud applications such as Google Apps, Microsoft Office 365, Dropbox, Amazon Cloud Drive and Box Enterprise. These are not specifically designed for the construction industry, but for businesses in general and can be adopted by any type of business.

One of the most basic cloud applications is data storage in the cloud, which companies such as Dropbox and Amazon Cloud Drive provide. This function basically means storing 
files, documents, photos, etc. in the cloud. The main advantage of this type of application is that the files stored in the cloud can be accessed from anywhere through the service provider's website when you log in to your account. Applications can also be downloaded on desktops and mobiles for easy synchronisation and management of files. On the desktop, the application will just be a folder where files can be stored and accessed while automatically synced to the cloud.

Another advantage of this type of application is the file sharing option. The files stored in the cloud can be shared with other users that are using the application through an invitation. The files shared can also be updated or edited and be synced across the cloud to all users who have access to that file. Using this function, a business can share documents and be constantly updated with the latest versions of the documents. These types of services for data storage are normally free, but with limited storage space. Users are charged if extra space is needed.

Moving on, there are more comprehensive cloud applications that are available for businesses that offer a wide range of functions, such as Google Apps and Microsoft Office 365. Applications such as email, calendars, online storage, document editing, website editing, video chat and messaging can all be accessed through the service provider's website. These applications are called web apps as they can be accessed from a website with a web browser.

Through this type of application, users are able to access and use the applications and also share anything from the applications with people who are in their contact list. Items such as calendar schedules and documents can be shared for easy communication and information flow. Discussions can also be conducted through online messaging, video calls or even simple post notes on documents and calendars. 
Businesses who use this type of application are charged based on a per user per month basis. This way, businesses can be flexible in determining how many people in the company or project should have access to the applications.

\section{Applications of Cloud BIM}

BIM has been in the construction industry for quite some time now, but the adoption and implementation level is still rather low. In an earlier part of the literature review, it was stated that the way forward for BIM will be with cloud computing. Currently, there are already BIM products in the market with cloud computing capabilities. However, there are two distinct approaches to implementation of BIM with cloud computing. In the first approach the model developed from BIM is in the cloud, whereas in the second approach the BIM software is virtualized in the cloud.

In the first approach to cloud BIM, there are products such as BIMx. BIMx is a normally designed software that is installed and used in a computer. However, it has additional functionalities that can enable the model developed or designed to be shared in the cloud. This model can be shared by uploading the model to the BIMx website through a web browser. The uploader can decide whether the model shared is to be private or public. A private file will require a username and password to view the model. The models and files can be viewed through a web browser or through a mobile application that BIMx has developed.

Next, BIMserver enables users to transform any computer into a BIM server, after which the files located in the server will be accessible through a web browser. BIMserver is a free open source software developed to encourage parties in the AEC industry to collaborate more efficiently and effectively. BIMserver is mainly intended to transform a computer into a file sharing server but with the ability to analyse Industry Foundation Classes (IFC) data and files. 
The compliant of IFC is important to BIM in terms of facilitating interoperability from various inputs under a neutral and license free file format specification that is not owned by any vendors. This means that it will be able to understand design files and the elements in them. With this added ability, the software is able to detect changes in the design of the models or files uploaded. With added plug-ins to the software, the user will also be able to visualise the model in 3D and to have a clash detection ability. Because it is an open source software, users are also free to develop additional features as they see fit.

The second approach to cloud BIM is through virtualization of the BIM software as a whole. Companies such as Autodesk have developed a whole platform for BIM in the cloud. Autodesk has a product called Autodesk 360 which combines cloud technology, BIM and other applications such as Project Lifecycle Management applications for the users. Users have a choice of installing the BIM software in their computers or using it through a web browser with the virtualized software. The main advantage of having virtualized software and applications is that operations such as rendering and simulation can be running in the cloud even when the user switches off his computer or does something else.

Other companies such as CaddForce and BIM9 provide entirely virtualized desktops with BIM and design software in the virtual desktop. These virtualized desktops are entire operating systems such as Windows 7 with all the necessary software and are accessible through a login tool on the user's desktop. These companies also develop hardware for companies that want to move into the cloud. For example, CaddForce has a compact CPU with minimum requirements that only runs virtualized desktops, whereas BIM9 helps companies to set up private clouds in their office.

Last but not least, Onuma System is another popular and IFC compliant cloud computing for BIM application for architecture and planning projects. The application works effectively for project management and planning based on the integrated model server for BIM in the 
cloud. It can also links with other desktop BIM applications such as ArchiCAD, and Revit. In sum, BIM has been said to be the next big leap for technology innovation in the construction industry. The authors feel that with cloud computing technology, BIM can help propel innovation and collaboration in the construction industry even further.

\section{Cloud project management applications}

Project Management applications and software have been around for a long time in the built environment. The applicants and software are important to a project success, where it is able to enhance the project managers' competency and skills. Applications such as Microsoft Project and WBS have been used by industry players to properly manage their construction projects since the introduction of IT. However, one of the limitations of these software is that they must be installed in a computer and are only usable in that computer. There is also no interconnectivity between parties using the software. Most of the time, there is a disconnection between site personnel and personnel in the headquarters or between parties of a project such as the contractor, architect and client. With the introduction of cloud computing, project management applications and software have been moving to the cloud, opening up a wide range of new functions and possibilities. The authors have found roughly 31 of these applications.

Across all the applications and software reviewed, the main similarity is that they are all web browser accessible. This is understandable, as it is the easiest way a cloud application can be accessed as it does not require any additional tools. The applications can normally be accessed through the product website with a username and password that are given when the licence of the application is purchased. Most of the applications also have mobile access, with the application accessible through mobile phones and tablets, through either a web browser or 
a custom application. Autodesk Buzzsaw, Projectmates and Paskr are a few of the products with custom applications.

Another common feature of the applications is the document management feature. This feature allows users to upload and store documents and files in the application. These documents can then be shared with other users of the application. This allows systematic control and management of the documents of a project without the need for physical paper copies. As a cloud application, this also creates a central database where documents can be accessed from anywhere by any users.

The next common feature of many applications is the reporting feature. The reporting feature allows users to prepare and submit reports such as daily, weekly and monthly progress reports. It also lets users submit reports such as request for information (RFIs). This helps to keep track of the work and progress of projects, as well as getting the most up-todate information.

Scheduling and budgeting are also two common features among many applications. The scheduling function in the applications is similar to work programme applications such as WBS and Microsoft Project, where the work programme and scheduling of works can be planned. On the other hand, the budgeting function is a costing and estimating feature where users can prepare a budget for their project. The budgeting function here is mainly for budgeting the construction costs of a project, which includes material, labour and subcontractor costs.

Several applications were found to have less common features such as tender management and finance management. The tender management feature can be used by both developers and contractors. Developers can use it to send out invitations to tender and can evaluate tenders through it, whereas contractors can track the tenders they are bidding for and manage their resources accordingly. On the other hand, the finance management feature is 
used to manage the accounting and finance part of the project, such as the cash flow of the company. This is different from the budgeting function described earlier, which is mainly for costing, but is interlinked in some of the applications for greater efficiency.

Besides the common and uncommon features, a number of applications also had specialised and rarer features. These features are thought to be designed to make the application stand out from the numerous alternative applications. The first few of these rare features are related to design and drawing. They allow integration with design software, a drawing viewer and markup, BIM model integration and drawing management. The integration with design software feature is only available on Autodesk Buzzsaw, as it is integrated with other Autodesk design software. The drawing viewer and markup are available with only three applications and they allow users to view drawings through the cloud application and also to mark the drawings with notes and annotations. The BIM model integration feature, on the other hand, allows users to view BIM models through the application. Finally, the drawing management feature allows users to upload and share drawings through the application.

Document management was described earlier as one of the most common features in all of the applications, but these documents could not be edited and could only be edited once downloaded from the database using traditional software. However, a few of the applications reviewed have a feature which lets users edit the documents in the cloud through the application. This document editing feature is only available in four out of the 31 applications.

Several other specialised features are change management, lead management, contract management and sub-contract management. Change management is used to manage variable orders that may arise in a project. With this feature, variable orders can be keyed into the application and these changes will be detected by the application. The total changes in costs can then be clearly calculated and shown. Thus, the overall budget of the project can be 
adjusted accordingly. Lead management is a feature which allows users to detect job opportunities through the internet. This particular feature is designed for contractors to constantly search for jobs in the market. The feature is currently only featured on BuildTopia. The next two features are for contract and sub-contract management. Contract management is for contractors to manage the current on-going contracts for their projects, whereas subcontract management is for contractors to manage their sub-contracts with the sub-contractors they have hired. Payments to sub-contractors can also be managed through this feature.

Another rare feature is a workflow management and task management feature. This is slightly different from the scheduling feature as it is a guided process for a project workflow. For example, it helps create a project during start-up, then automatically guides the user towards the necessary actions to be taken, such as requiring an admin punch list of the parties involved, and leads to the design input of the architect and engineer. The scheduling feature is more of a manual spreadsheet for users to customise and key in the necessary works. The task management feature, however, is more of a check-list feature for users to list tasks that must be done.

Two other rare features are procurement and inventory management. The procurement feature allows users to directly send out purchase orders to suppliers through the application and network available, so as to procure the necessary materials and resources. On the other hand, inventory management is mainly for contractors to keep tabs on their inventory.

Besides that, some other features available are service and warranty management, human resource management and material approval. The service and warranty management feature is used by contractors to keep track of all service and warranty claims that may arise after practical completion of projects. Through this, contractors can easily manage and solve any claims that may arise. The human resource management is also a feature mainly for contractors to keep track of their labour. Working hours can be clocked in through this 
feature and this can then be used to calculate and pay their salaries. Finally, the material approval feature allows contractors to submit material for approval from the client or architect for use in the project.

The other features that were reviewed on the applications are non-project management or construction related as they are mainly additional functions that the applications have for users. Some of these aim to increase the reliability and security of the application, for example, encrypted data, admin control, 99.9\% uptime and archiving. This means that all data and information uploaded are protected with encryption and also the applications are usable $99.9 \%$ of the time. Furthermore, with admin control, the administration can effectively control the abilities of the users in the application. For a contingency plan, the archiving feature can be used to create an archive of all the data uploaded in the cloud for safe-keeping in local servers, drivers or compact discs.

Besides that, a few of the applications also have additional features that can assist the productivity and convenience of the user. These include an activity log, online messaging, email, trade network, contact list and calendar. With the activity log feature, users can have a history of activities that were done with the application. In this way, mistakes can be properly tracked back to a time, date and location. With online messaging and e-mail, users can also keep in contact with each other seamlessly in real time. A contact list feature in some applications also allows users to save a list of contacts for the projects. Certain applications even have established trade networks of parties in the construction industry that can be accessed by users. As an added bonus, some applications also feature a calendar for easy reference and planning by the user.

With numerous software and applications available and already in existence, some developers have designed their applications to be able to integrate with other applications, for 
example, for integration with Microsoft Office software, Microsoft Dynamics SL accounting, etc. This means that the software already purchased by users will not go to waste.

Apart from that, there are also several unique features that are not in the majority of the available applications. One such feature is website integration. With the internet fast becoming the top source of media, companies of all types and sizes need to have a website. Taking advantage of this fact, BuiltTopia has website integration in their application to allow users to create their own website through it. Another unique feature is presented by ThresholdCM, where the application enables users to tag photos to drawings, allowing a clear representation of the work progress and physical appearance.

Lastly, while most of the applications mainly provide software, two companies provide both hardware and software for users. This is done through the company providing desktop virtualization, where the whole desktop experience is in the cloud. In addition, the company provides inexpensive hardware that is specially designed for cloud use. Besides this, the company also allows users the option of having traditional software installed, allowing for offline access, and giving the option of customisation of the software.

Project Management software have been around for a long time, ever since the IT and ICT industry boom. However, the construction industry has been one of the few industries that are still lagging behind in terms of IT and ICT adoption. With the internet and cloud computing coming into play, cloud project management applications are becoming more easily accessible. With numerous options and choices currently available in the market, parties have the freedom of choice in selecting the most appropriate application.

Table 2 shows that the two applications with the most features are Google Apps and Microsoft Office 365, while the other three applications have fewer features. This is because Google Apps and Microsoft Office 365 are designed to have many productivity tools for business to use, while the other three applications are of data and file storage applications. 


\section{Cloud BIM applications}

A total of six cloud BIM applications were compared in this paper, namely Autodesk BIM 360, Cadd Force, BIM9, BIMServer,BIMx and Onuma System. All of the applications fulfil the definition of a BIM which enables digital representation of the physical and functional characteristics of a facility. The models can also be shared through the cloud with these applications. Table 3 shows a comparison of the applications.

It can be clearly seen that Autodesk BIM 360 offers the most features, while Onuma System, Cadd Force, BIM9 and BIMServer all provide a considerable number of features, and BIMx provides the fewest features.

Autodesk BIM 360 is mainly a design software with all the designing functions. On top of that, it has added cloud computing capabilities, giving it the most features. Thus, the application can be either installed in the computer or used through the cloud, offering users the best of both worlds.

Onuma System has numerous functions in its cloud computing features too. The strength of the application is for architectural use and also the project management aspect. It works well for program and project development. The data from other vendors can be imported or exported in this application.

Cadd Force and BIM9, on the other hand, use a different approach to cloud computing with virtualized desktops. This means minimum hardware is needed and everything is done through the cloud. It also provides a lot of flexibility and gives users the freedom to add on other types of software besides the BIM application if needed.

The next application is BIMServer, which is a free open source BIM software that enables users to create a BIM cloud of their own. This cloud can be either a private cloud or through a cloud service provider. This application is mainly a file and BIM sharing 
application which lets users collaborate in a project. Finally, BIMx is actually an extension application for Graphisoft's ArchiCAD software, which enable users to share the BIM model through the cloud. This means that both BIMServer and BIMx still require conventional design software for drawing and design work to be done before a model can be generated.

\section{Cloud project management applications}

Through the course of this research, numerous project management applications have been found, with many being cloud applications. A considerable number of cloud project management applications are available in the market, from which the authors have selected thirty one for review and comparison. The applications that were reviewed and compared are listed in Table 4.

Comparison of the cloud project management application features is presented in a table format to clearly show the features that each of the applications has, as can be seen in Table 5 below. The first column of the table consists of the various features that the applications have, while the numbers in the first row represent the corresponding applications in Table 4.

From the table, it can be seen that there are several features that are common to and available in most of the applications. However, there are rare and unique features that only some applications provide. These unique features are more innovative, and may be an attempt by the developers to add further value to their products in a competitive market.

\subsection{Objective 2: Decision-Making Model}

With the data collected and a comparison made of the applications, a decision-making model was developed to assist interested parties in the built environment in selecting an appropriate and suitable application that best fit their needs. 
The model was based on the type and size of company, as illustrated in Figure 2. The first section of the model has been separated into two categories, namely the developer and project managers, and contractors. The contractor category is further separated into small and large firms. Each of the categories will then have a list of the general, BIM and project management cloud applications that are suitable for use.

For the developer and project management category, almost all the general cloud applications are suitable, except for Amazon Drive. This is because Amazon Drive is designed for personal use and does not have alternative plans for businesses, as a result of which there is not enough space for the needs of a medium to large company, whereas the other applications have plans designed for business and enterprise use.

The cloud BIM applications are suitable for developers and project managers as they are the main decision-makers in a project. Thus, it is important for them to have as much information as possible to assist them in this work. Cloud BIM and traditional BIM applications also require a central figure to first establish and coordinate all parties that are to participate and collaborate with the application. Thus, the developer and project manager must be the key figures in doing this.

On the other hand, for project management, only twenty one out of the thirty one applications are suitable for use by developers and project managers. This is because the applications have the necessary features to enable proper management of a project as a whole, keeping track of the overall project progress and also as a medium to distribute the necessary information to the relevant parties of the project. These key features include tender and bid management, document management, reporting and scheduling functions.

Moving to the small contractors' category, this category consists of small sub-contractors and contractors such as home renovators. Parties in this category should use all the general cloud applications, as it is the easiest and most user-friendly cloud applications that can 
increase their productivity. However, the cloud BIM applications are not suitable, as they are mainly for use in large projects.

For cloud project management, twenty seven out of the thirty one applications are suitable for use. The four applications that are unsuitable for use are Autodesk Buzzsaw, Autodesk Constructware, Prolog and Proliance, which are mainly designed for large projects and have many additional features that are redundant for small contractors. Applications such as Threshold CM, Builder Trend, Co-Construct and Jobnimbus are more suitable as they are designed for home-builders and renovators, with features such as photo tagging to drawings, and custom material selection for clients.

Eventually, for the large contractors, the suitable general and BIM cloud applications are identical to those for developers, as they are both involved in large projects and are the key central figures in using BIM. Almost all of the project management applications are also suitable for the same reasons, except for the few applications mentioned earlier that are designed for home-builders and renovators.

\section{Discussion}

A total of forty two cloud computing applications were reviewed in this paper, of which five were general cloud applications, six were cloud BIM applications and thirty one were cloud project management applications. Certain limitations need to be considered. Some of the information and data regarding the applications were gathered from the websites of the products, brochures and video tutorials of the applications. Even though some applications have been purchased and tested under full/free licenses and trial versions, it is still rather impossible to assess all of the applications thoroughly as most of the applications require a certain level of learning curve and time for using the applications. Nevertheless, the actual 
testing and using of the applications would reduce the bias of the information as advertised, which only the best qualities of the applications will be promoted.

As the cloud computing market is fast becoming a very competitive market, many applications also tend to be more secretive and do not post many actual pictures of their application interface or details of the features of their products, as fearing of their competitors in copying the product. Furthermore, the prices of many applications, especially for cloud project management applications, are also not available due to the competitive nature of the market. The competition might hinder the data collection process. Nonetheless, the competitive situation is necessary for the sake of the growth of cloud computing.

Besides, the decision making model is purely to assist the users in selecting the cloud computing applications in the built environment. The selection might be superficial at this stage as only considering the type and size of companies towards the cloud computing applications. More informed decisions can be achieved by analysing the matrix among the variables of project characteristics, company backgrounds, budget, and the applications' features.

Apart from that, after investigating the relatively big number of cloud computing applications, it is also recommended that open standards should be applied in the applications to facilitate standardized passing of information between systems or vendors. A centralized web hosted database can be an option to cultivate transparency and long term development of cloud computing, yet the ownership or intellectual property should be properly drafted in the agreement in advance [22]. In sum, that the research discovers that many applications are already available and easily accessible. It can also be clearly seen that most of the applications require significant collaborations among project stakeholders, which is an effective means to reduce and overcome fragmentation practices in the built environment. 


\section{Conclusion}

The explanatory case study has reviewed and identified forty two cloud computing applications that are suitable in the built environment. The summary of the results is as follow:

- The applications have been compared and grouped into three categories, such as, five general cloud applications, six cloud BIM applications and thirty one cloud project management applications. The applications were then critically analysed for their pros and cons in the first section of the analysis.

- Google Apps, Microsoft Office 365 and Box Enterprise are the commonly available general cloud applications with the most features. On the other hand, Autodesk BIM 360, BIMServer and BIM9 are common cloud BIM applications; and Viewpoint and Prolog have the most features in their cloud project management applications.

- Subsequently, the decision making model has been developed and discovered many possible cloud computing applications in various disciplines. The findings show that developers, project managers and large contractors have more options to choose from, as BIM and many project management applications are designed for large projects.

\section{References}

[1] M. Armburst, A. Fox, R. Griffith, A.D. Joseph, R.H. Katz, A. Konwinski, G. Lee, D.A. Patterson, A. Rabkin, I. Stocia, M. Zaharia, Above the Clouds: a Berkeley View of Cloud Computing, Electrical Engineering and Computer Sciences University of California at Berkeley, 2009, http://www.cs.columbia.edu/ roxana/teaching/COMS-E6998-7-Fall-2011/papers/armbrust-tr09.pdf.

[2] Y. Arayici, P. Coates, L. Koskela, M. Kagioglou, C. Usher, K. O'reilly, Technology adoption in the BIM implementation for lean architectural practice, Automation in Construction 20 (2) (2011)

[3] 189-195. S. Azhar, M. Hein, B. Sketo, Building information modeling (BIM): Benefits, risks and challenges, Proceedings of the 44th ASC National Conference, 2008.

[4] S. Bhardwaj, L. Jain, S. Jain, Cloud computing: A study of infrastructure as a service (IAAS), International Journal of engineering and information Technology 2 (1) (2010) 60-63. 
[5] J. Blatter, M. Haverland, Two or three approaches to explanatory case study research?, Annual Meeting of the American Political Science Association, New Orleans, 2012, 1-18.

[6] A. Caballero, S. Ahmed, S. Azhar, M. Barcala, Development of an information model to enhance integration and coordination in the construction projects, NIST SPECIAL PUBLICATION SP (2003) 123-128.

[7] J.C. Cheng, K.H. Law, H. Bjornsson, A. Jones, R. Sriram, A service oriented framework for construction supply chain integration, Automation in Construction 19 (2) (2010) 245-260.

[8] H.-L. Chi, S.-C. Kang, X. Wang, Research trends and opportunities of augmented reality applications in architecture, engineering, and construction, Automation in Construction (2013).

[9] Cloud Computing Use Case Discussion Group, Cloud Computing Use Cases White Paper, 2010, http://opencloudmanifesto.org/Cloud_Computing_Use_Cases_Whitepaper-4_0.pdf

[10] J.M. Conejero, R. Rodríguez-Echeverría, F. Sánchez-Figueroa, M. Linaje, J.C. Preciado, P.J. Clemente, Re-engineering legacy Web applications into RIAs by aligning modernization requirements, patterns and RIA features, Journal of Systems and Software 86 (2013) 2981-2994.

[11] P. Dorey, A. Leite, Commentary: Cloud computing-A security problem or solution?, information security technical report 16 (3) (2011) 89-96.

[12] N. Gu, K. London, Understanding and facilitating BIM adoption in the AEC industry, Automation in Construction 19 (8) (2010) 988-999.

[13] Y. Jiao, S. Zhang, Y. Li, Y. Wang, B. Yang, Towards cloud Augmented Reality for construction application by BIM and SNS integration, Automation in Construction (2012) 37-47.

[14] M. Kagioglou, R. Cooper, G. Aouad, M. Sexton, Rethinking construction: the generic design and construction process protocol, Engineering construction and architectural management 7 (2) (2000) 141-153.

[15] D. Maga, M. Hiebel, C. Knermann, Comparison of two ICT solutions: Desktop PC versus thin client computing, International Journal of Life Cycle Assessment 18 (2013) 861-871.

[16] S. Marston, Z. Li, S. Bandyopadhyay, J. Zhang, A. Ghalsasi, Cloud computing-The business perspective, Decision Support Systems 51 (1) (2011) 176-189.

[17] P. Mell, T. Grance, The NIST definition of cloud computing (draft), NIST special publication 800 (145) (2011) 7 . 
[18] National Institute of Standards and Technology, The NIST Definition of Cloud Computing, 2011, http://csrc.nist.gov/publications/nistpubs/800-145/SP800-145.pdf.

[19] X. Park, C., Lee, D., Kwon, O., Wang, A Framework for Proactive Construction Defect Management using BIM, Augmented Reality and Ontology-based Data Collection Template, Automation in Construction 33 (2013) 61-71, 2013.

[20] V. Rathore, J. Yoo, J. Lee, S. Hong, Providing network performance isolation in VDEbased cloud computing systems, Proc.- 2011 IEEE International Conference on HPCC 2011 - 2011 IEEE International Workshop on FTDCS 2011 -Workshops of the 2011 Int. Conf. on UIC 2011- Workshopsof the 2011 Int. Conf. ATC 2011, 721-725, 2011.

[21] A. Redmond, A. Hore, M. Alshawi, R. West, Exploring how information exchanges can be enhanced through Cloud BIM, Automation in Construction 24 (2012) 175-183.

[22] A. Redmond, R. West, The use of cloud enabled building information models - an expert analysis, Australasian Journal of Construction Economics and Building 12(4) (2012) 53-67.

[23] D. Reeves, Cloud $\quad$ Computing: $\quad$ Transforming $\quad$ IT, http://www.msbiusergroupmn.org/dropzone/Forums/464/3415/Cloud\%20ComputingTransforming\%20IT.pdf.

[24] D.E.Y. Sarna, Implementing and developing cloud computing applications, in: T.F. Group (Ed.), Florida, 2011.

[25] A. Sawhney, J.U. Maheswari, Design Coordination Using Cloud-based Smart Building Element Models, International Journal of Computer Information Systems and Industrial Management Applications 5 (2013) 445-453.

[26] V. Singh, N. Gu, X. Wang, A theoretical framework of a BIM-based multi-disciplinary collaboration platform, Automation in Construction 20 (2) (2011) 134-144.

[27] Software \& Information Industry Association (SIIA), Guide to Cloud Computing for Policymakers, 2011, http://siia.net/index.php?option=com_docman\&task=doc_download\&gid=3040\&Itemid=318 .

[28] N.A. Sultan, Reaching for the "cloud”: How SMEs can manage, International journal of information management 31 (3) (2011) 272-278.

[29] J. Tao, H. Marten, D. Kramer, W. Karl, An intuitive framework for accessing computing clouds, Procedia Computer Science 4 (2011) 2049-2057. 
[30] X. Wang, M. Truijens, L. Hou, Y. Wang, Y. Zhou, Integrating Augmented Reality with Building Information Modeling: Onsite construction process controlling for liquefied natural gas industry, Automation in Construction 40 (2014) 96-105.

[31] Y. Wang, X. Wang, J. Wang, P. Yung, G. Jun, Engagement of facilities management in design stage through BIM: framework and a case study, Advances in Civil Engineering 2013 (2013), 1-8.

[32] I. Wu, S.-H. Hsieh, A framework for facilitating multi-dimensional information integration, management and visualization in engineering projects, Automation in Construction 23 (2012) 71-86.

[33] Y. Xu, Y. Lu, A.P. Chan, M.J. Skibniewski, J.F. Yeung, A computerized risk evaluation model for public-private partnership (PPP) projects and its application, International Journal of Strategic Property Management 16 (3) (2012) 277-297.

[34] S. Zhang, H. Yan, X. Chen, Research on Key Technologies of Cloud Computing, Physics Procedia 33 (2012) 1791-1797. 


\section{APPENDIX: List of Cloud Applications}

A. General Cloud Applications

1. Google apps (http://www.google.com/enterprise/apps/business/)

2. Microsoft office 365 (http://www.microsoft.com/en-us/office365/small-business-home.aspx)

3. Dropbox (https://www.dropbox.com/)

4. Amazon cloud drive (http://www.amazon.com/gp/feature.html?ie=UTF8\&docId=1000796931)

5. Box enterprise (https://www.box.com/business/features/)

\section{B. Cloud BIM Applications}

1. Autodesk BIM 360 (http://usa.autodesk.com/adsk/servlet/pc/index?siteID=123112\&id=19676436)

2. Cadd force (http://www.caddforce.com/products.php)

3. BIM9 (http://bim9.com/)

4. BIM server (http://bimserver.org/)

5. BIMx (https://bimx.graphisoft.com/)

6. Onuma System (http://www.onuma.com/products/OnumaPlanningSystem.php)

\section{Cloud Project Management Applications}

1. Autodesk Buzzsaw (http://usa.autodesk.com/buzzsaw/)

2. Autodesk Constructware (http://usa.autodesk.com/adsk/servlet/pc/index?siteID=123112\&id=7104129)

3. Conject (http://www.conject.com/de/en/applications-pm)

4. BuildTopia (http://www.buildtopia.com/Default.aspx

5. Jonas Premier (http://www.jonas-construction.com/Products/Premier.aspx/)

6. Mclaren Fusion Live (http://www.mclarensoftware.com/solutions/mclaren-fusionlive.aspx)

7. eBid systems (http://www.ebidsystems.com/)

8. Eadoc (http://www.eadocsoftware.com/)

9. Procore (http://www.procore.com/)

10. e-builder (http://www.e-builder.net/)

11. built it live (http://www.builditlive.com/)

12. Aconex (http://www.aconex.com/)

13. Projectmates (http://www.projectmates.com/Portal2007/Products/Construction.aspx)

14. eSUB (http://www.esubinc.com/esub-construction-project-management-software.html)

15. iSqFt (http://www.isqft.com/new/)

16. Jetstream (http://www.jetstreamapp.com/construction_software_features.html)

17. ThresholdCM http://www.thresholdcm.com/)

18. PMWeb (http://pmweb.com/Pages/)

19. Builder Trend (http://www.buildertrend.com/softwaresolutions.aspx)

20. Co-construct (http://www.co-construct.com/)

21. Paskr (http://www.paskr.com/features)

22. Owner insite (http://www.owner-insite.com/)

23. Spitfire PM http://www.spitfiremanagement.com/software/software.htm

24. Build tools http://www.buildtools.com/features/

25. Viewpoint http://www.viewpointcs.com/cloud.aspx

26. Job Nimbus http://www.jobnimbus.com/

27. AccuBuild http://www.accu-build.com/

28. Simplex VPO http://www.simplexgroup.com/vpo

29. Construct Job http://www.accubid.com/products/constructjob_mech.htm

30. Prolog http://www.meridiansystems.com/products/prolog/overview/

31. Proalliance http://www.meridiansystems.com/products/proliance/overview/ 


\section{List of Tables}

Table 1: Ten obstacles and opportunities for the growth of cloud computing [1]

\begin{tabular}{|c|l|l|}
\hline No & Obstacles & \multicolumn{2}{l|}{ Opportunities } \\
\hline & Adoption Aspects & $\begin{array}{l}\text { Use Multiple Cloud Providers to provide Business Continuity; } \\
\text { Use Elasticity to Defend Against DDOS attacks }\end{array}$ \\
\hline 1 & Availability of Service & $\begin{array}{l}\text { Standardize APIs; Make compatible software available to } \\
\text { enable Surge Computing }\end{array}$ \\
\hline 2 & Data Lock-In & $\begin{array}{l}\text { Deploy Encryption, VLANs, and Firewalls; Accommodate } \\
\text { National Laws via Geographical Data Storage }\end{array}$ \\
\hline 3 & Data Confidentiality and Auditability & $\begin{array}{l}\text { FedExing Disks; Data Backup/Archival; Lower WAN Router } \\
\text { Costs; Higher Bandwidth LAN Switches }\end{array}$ \\
\hline 4 & Technical Aspects & $\begin{array}{l}\text { Improved Virtual Machine Support; Flash Memory; Gang } \\
\text { Scheduling, VMs for HPC apps }\end{array}$ \\
\hline 5 & Performance Unpredictability & Invent Scalable Store \\
\hline 6 & Scalable Storage & Invent Debugger that relies on Distributed VMs \\
\hline 7 & Bugs in Large-Scale Distributed & $\begin{array}{l}\text { Invent Auto-Scaler that relies on Machine Learning; } \\
\text { Snapshots to encourage Cloud Computing Conservationism }\end{array}$ \\
\hline 8 & Scaling Quickly & \multicolumn{2}{|l}{} \\
\hline & Policy and Business Aspects & Offer reputation-guarding services like those for email \\
\hline 9 & Reputation Fate Sharing & Pay-for-use licenses; Bulk use sales \\
\hline 10 & Software Licensing &
\end{tabular}


Table 2: Comparison of features of general cloud applications

\begin{tabular}{|l|c|c|c|c|c|}
\hline Features Applications & $\begin{array}{l}\text { Google } \\
\text { Apps }\end{array}$ & $\begin{array}{l}\text { Microsoft } \\
\text { Office 365 }\end{array}$ & Dropbox & $\begin{array}{l}\text { Amazon } \\
\text { Drive }\end{array}$ & $\begin{array}{l}\text { Box } \\
\text { Enterprise }\end{array}$ \\
\hline Email & $\sqrt{ }$ & $\sqrt{ }$ & & & \\
\hline Calendar & $\sqrt{ }$ & $\sqrt{ }$ & & & \\
\hline Calendar sharing & $\sqrt{ }$ & $\sqrt{ }$ & $\sqrt{ }$ & $\sqrt{ }$ \\
\hline File storage & $\sqrt{ }$ & $\sqrt{ }$ & & & \\
\hline Online Document Editing & $\sqrt{ }$ & $\sqrt{ }$ & $\sqrt{ }$ & & $\sqrt{ }$ \\
\hline Encrypted Data & $\sqrt{ }$ & $\sqrt{ }$ & $\sqrt{ }$ & & $\sqrt{ }$ \\
\hline Pay per user per month & $\sqrt{ }$ & $\sqrt{ }$ & $\sqrt{ }$ & $\sqrt{ }$ \\
\hline Pay for storage space & $\sqrt{ }$ & $\sqrt{ }$ & $\sqrt{ }$ & \\
\hline High Uptime & $\sqrt{ }$ & $\sqrt{ }$ & & & $\sqrt{ }$ \\
\hline Online Messaging & $\sqrt{ }$ & $\sqrt{ }$ & & & $\sqrt{ }$ \\
\hline Video Chat & & $\sqrt{ }$ & & $\sqrt{ }$ & $\sqrt{ }$ \\
\hline Website Publication & $\sqrt{ }$ & $\sqrt{ }$ & $\sqrt{ }$ & $\sqrt{ }$ \\
\hline Mobile app & $\sqrt{ }$ & $\sqrt{ }$ & $\sqrt{ }$ & $\sqrt{ }$ \\
\hline File sharing & $\sqrt{ }$ & $\sqrt{ }$ & $\sqrt{ }$ & $\sqrt{ }$ \\
\hline Syncrhonisation across account & $\sqrt{ }$ & $\sqrt{ }$ & $\sqrt{ }$ & $\sqrt{ }$ \\
\hline Free trial & $\sqrt{ }$ & $\sqrt{ }$ & $\sqrt{ }$ & $\sqrt{ }$ \\
\hline Web-browser access & $\sqrt{ }$ & $\sqrt{ }$ & & & $\sqrt{ }$ \\
\hline Comment section for files & $\sqrt{ }$ & & & & \\
\hline Project Specific Websites & $\sqrt{ }$ & $\sqrt{ }$ & & $\sqrt{ }$ & \\
\hline Addtional supporting apps & $\sqrt{ }$ & $\sqrt{ }$ & & & \\
\hline Administrative control & & & & & \\
\hline
\end{tabular}


Table 3: Comparison of features of cloud BIM applications

\begin{tabular}{|c|c|c|c|c|c|c|}
\hline $\begin{array}{ll}\text { Features } & \text { Applications } \\
\end{array}$ & $\begin{array}{l}\text { Autodesk } \\
\text { BIM } 360\end{array}$ & $\begin{array}{l}\text { Cadd } \\
\text { Force }\end{array}$ & BIM9 & BIMServer & BIMx & $\begin{array}{l}\text { Onuma } \\
\text { System }\end{array}$ \\
\hline $\begin{array}{l}\text { Clash Detection and } \\
\text { Coordination }\end{array}$ & $\sqrt{ }$ & & & $\sqrt{ }$ & & \\
\hline Design tools & $\sqrt{ }$ & $\sqrt{ }$ & $\sqrt{ }$ & & & $\sqrt{ }$ \\
\hline Field management tools & $\sqrt{ }$ & & & & & \\
\hline Energy Analysis & $\sqrt{ }$ & & & & & $\sqrt{ }$ \\
\hline Structural Analysis & $\sqrt{ }$ & & & & & \\
\hline 3D Visualization & $\sqrt{ }$ & & & $\sqrt{ }$ & $\sqrt{ }$ & $\sqrt{ }$ \\
\hline Online File Storage & $\sqrt{ }$ & $\sqrt{ }$ & $\sqrt{ }$ & & & $\sqrt{ }$ \\
\hline Online drawing viewing & $\sqrt{ }$ & $\sqrt{ }$ & $\sqrt{ }$ & & $\sqrt{ }$ & $\sqrt{ }$ \\
\hline Online drawing editing & $\sqrt{ }$ & $\sqrt{ }$ & $\sqrt{ }$ & & & $\sqrt{ }$ \\
\hline Encrypted data & $\sqrt{ }$ & & & & & $\sqrt{ }$ \\
\hline Online sharing of files & $\sqrt{ }$ & $\sqrt{ }$ & $\sqrt{ }$ & $\sqrt{ }$ & $\sqrt{ }$ & $\sqrt{ }$ \\
\hline Simulations & $\sqrt{ }$ & & & & & $\sqrt{ }$ \\
\hline $\begin{array}{ll}\text { Product } & \text { Lifecycle } \\
\text { Management } & \end{array}$ & $\sqrt{ }$ & & & & & $\sqrt{ }$ \\
\hline Hardware support & & $\sqrt{ }$ & $\sqrt{ }$ & & & $\sqrt{ }$ \\
\hline Virtualized desktop & & $\sqrt{ }$ & $\sqrt{ }$ & & & $\sqrt{ }$ \\
\hline Web-browser access & $\sqrt{ }$ & & & $\sqrt{ }$ & & $\sqrt{ }$ \\
\hline Offline access & $\sqrt{ }$ & & & & $\sqrt{ }$ & \\
\hline Mobile apps & $\sqrt{ }$ & & $\sqrt{ }$ & & $\sqrt{ }$ & $\sqrt{ }$ \\
\hline Additional supporting apps & $\sqrt{ }$ & $\sqrt{ }$ & $\sqrt{ }$ & & & $\sqrt{ }$ \\
\hline Private cloud & & & $\sqrt{ }$ & $\sqrt{ }$ & & $\sqrt{ }$ \\
\hline File management system & $\sqrt{ }$ & & & $\sqrt{ }$ & $\sqrt{ }$ & $\sqrt{ }$ \\
\hline IFC file recognition & & & & $\sqrt{ }$ & & $\sqrt{ }$ \\
\hline Change detection & & & & $\sqrt{ }$ & & \\
\hline Free trial & $\sqrt{ }$ & $\sqrt{ }$ & $\sqrt{ }$ & & & \\
\hline Free open source software & & & & $\sqrt{ }$ & & \\
\hline
\end{tabular}


Table 4: List of cloud project management applications

\begin{tabular}{|c|l|c|l|}
\hline No & \multicolumn{1}{|c|}{ Application } & No & \multicolumn{1}{|c|}{ Application } \\
\hline 1 & Autodesk Buzzsaw & 17 & Threshold CM \\
\hline 2 & Autodesk Constructware & 18 & PMWeb \\
\hline 3 & Conject PM & 19 & Builder Trend \\
\hline 4 & Build Topia & 20 & Co-construct \\
\hline 5 & Jonas Premier & 21 & Paskr \\
\hline 6 & Mclaren Fusion Live & 22 & Owner Insite \\
\hline 7 & eBID Systems & 23 & $\begin{array}{l}\text { Spitfire Project } \\
\text { Managemet }\end{array}$ \\
\hline 8 & Eadoc & 24 & Builder Tools \\
\hline 9 & Procore & 25 & Viewpoint \\
\hline 10 & e-Builder & 26 & Jobnimbus \\
\hline 11 & Built it Live & 27 & Accubuild \\
\hline 12 & Aconex & 28 & Simplex VPO \\
\hline 13 & Projectmates & 29 & Trimble Construct Job \\
\hline 14 & eSUB & 30 & Prolog \\
\hline 15 & iSqFt & 31 & Proliance \\
\hline 16 & Jetstream & & \\
\hline
\end{tabular}


Table 5: Comparison of features of cloud project management applications

\begin{tabular}{|c|c|c|c|c|c|c|c|c|c|c|c|c|c|c|c|c|c|c|c|c|c|c|c|c|c|c|c|c|c|c|c|}
\hline $\begin{array}{l}\text { Applicat } \\
\text { ions } \\
\text { Features }\end{array}$ & 1 & 2 & 3 & 4 & 5 & 6 & 7 & 8 & 9 & $\begin{array}{l}1 \\
0\end{array}$ & $\begin{array}{l}1 \\
1\end{array}$ & $\begin{array}{l}1 \\
2\end{array}$ & $\begin{array}{l}1 \\
3\end{array}$ & $\begin{array}{l}1 \\
4\end{array}$ & $\begin{array}{l}1 \\
5\end{array}$ & $\begin{array}{l}1 \\
6\end{array}$ & $\begin{array}{l}1 \\
7\end{array}$ & $\begin{array}{l}1 \\
8\end{array}$ & $\begin{array}{l}1 \\
9\end{array}$ & $\begin{array}{l}2 \\
0\end{array}$ & $\begin{array}{l}2 \\
1\end{array}$ & $\begin{array}{l}2 \\
2\end{array}$ & $\begin{array}{l}2 \\
3\end{array}$ & $\begin{array}{l}2 \\
4\end{array}$ & $\begin{array}{l}2 \\
5\end{array}$ & $\begin{array}{l}2 \\
6\end{array}$ & $\begin{array}{l}2 \\
7\end{array}$ & $\begin{array}{l}2 \\
8\end{array}$ & $\begin{array}{l}2 \\
9\end{array}$ & $\begin{array}{l}3 \\
0\end{array}$ & $\begin{array}{l}3 \\
1\end{array}$ \\
\hline $\begin{array}{l}\text { Web } \\
\text { Browser } \\
\text { Access } \\
\end{array}$ & $\sqrt{ }$ & $\sqrt{ }$ & $\sqrt{ }$ & $\sqrt{ }$ & $\sqrt{ }$ & $\sqrt{ }$ & $\sqrt{ }$ & $\sqrt{ }$ & $\sqrt{ }$ & $\sqrt{ }$ & $\sqrt{ }$ & $\sqrt{ }$ & $\sqrt{ }$ & $\sqrt{ }$ & $\sqrt{ }$ & $\sqrt{ }$ & $\sqrt{ }$ & $\sqrt{ }$ & $\sqrt{ }$ & $\sqrt{ }$ & $\sqrt{ }$ & $\sqrt{ }$ & $\sqrt{ }$ & $\sqrt{ }$ & $\sqrt{ }$ & $\sqrt{ }$ & $\sqrt{ }$ & $\sqrt{ }$ & $\sqrt{ }$ & $\sqrt{ }$ & $\sqrt{ }$ \\
\hline $\begin{array}{l}\text { Mobile } \\
\text { access }\end{array}$ & $\sqrt{ }$ & & $\sqrt{ }$ & $\sqrt{ }$ & & $\sqrt{ }$ & & & $\sqrt{ }$ & $\sqrt{ }$ & & $\sqrt{ }$ & $\sqrt{ }$ & $\sqrt{ }$ & & & $\sqrt{ }$ & & $\sqrt{ }$ & $\sqrt{ }$ & $\sqrt{ }$ & $\sqrt{ }$ & $\sqrt{ }$ & $\sqrt{ }$ & $\sqrt{ }$ & & $\sqrt{ }$ & $\sqrt{ }$ & & $\sqrt{ }$ & $\sqrt{ }$ \\
\hline $\begin{array}{l}\text { Integrati } \\
\text { on with } \\
\text { Design } \\
\text { Software }\end{array}$ & $\sqrt{ }$ & & & & & & & & & & & & & & & & & & & & & & & & & & & & & & \\
\hline $\begin{array}{l}\text { Drawing } \\
\text { Viewer } \\
\& \\
\text { Markup } \\
\end{array}$ & $\sqrt{ }$ & & $\sqrt{ }$ & & & & & & & & & $\sqrt{ }$ & & & & & & & & & & & $\sqrt{ }$ & & & & & & & & \\
\hline $\begin{array}{l}\text { BIM } \\
\text { Model } \\
\text { integrati } \\
\text { on }\end{array}$ & $\sqrt{ }$ & & & & & & & & & & & $\sqrt{ }$ & & & & & & $\sqrt{ }$ & & & & & & & & & & & & $\sqrt{ }$ & \\
\hline $\begin{array}{l}\text { Docume } \\
\text { nt } \\
\text { Manage } \\
\text { ment }\end{array}$ & $\sqrt{ }$ & $\sqrt{ }$ & $\sqrt{ }$ & $\sqrt{ }$ & $\sqrt{ }$ & $\sqrt{ }$ & $\sqrt{ }$ & $\sqrt{ }$ & $\sqrt{ }$ & $\sqrt{ }$ & $\sqrt{ }$ & $\sqrt{ }$ & $\sqrt{ }$ & $\sqrt{ }$ & $\sqrt{ }$ & $\sqrt{ }$ & & $\sqrt{ }$ & $\sqrt{ }$ & $\sqrt{ }$ & $\sqrt{ }$ & $\sqrt{ }$ & $\sqrt{ }$ & $\sqrt{ }$ & $\sqrt{ }$ & & $\sqrt{ }$ & $\sqrt{ }$ & $\sqrt{ }$ & $\sqrt{ }$ & $\sqrt{ }$ \\
\hline $\begin{array}{l}\text { Docume } \\
\text { nt } \\
\text { Editing }\end{array}$ & & & & & $\sqrt{ }$ & & & & & & & & & & & & & & & & & & $\sqrt{ }$ & & & & & & & $\sqrt{ }$ & $\sqrt{ }$ \\
\hline $\begin{array}{l}\text { Scheduli } \\
\text { ng }\end{array}$ & & & & $\sqrt{ }$ & & $\sqrt{ }$ & & & $\sqrt{ }$ & $\sqrt{ }$ & $\sqrt{ }$ & & $\sqrt{ }$ & & & $\sqrt{ }$ & & $\sqrt{ }$ & $\sqrt{ }$ & $\sqrt{ }$ & & $\sqrt{ }$ & & $\sqrt{ }$ & & & $\sqrt{ }$ & & & $\sqrt{ }$ & $\sqrt{ }$ \\
\hline $\begin{array}{l}\text { Reportin } \\
\mathrm{g}\end{array}$ & $\sqrt{ }$ & & & & $\sqrt{ }$ & $\sqrt{ }$ & & $\sqrt{ }$ & $\sqrt{ }$ & $\sqrt{ }$ & $\sqrt{ }$ & $\sqrt{ }$ & $\sqrt{ }$ & $\sqrt{ }$ & & $\sqrt{ }$ & & $\sqrt{ }$ & & $\sqrt{ }$ & $\sqrt{ }$ & $\sqrt{ }$ & & $\sqrt{ }$ & $\sqrt{ }$ & & $\sqrt{ }$ & $\sqrt{ }$ & & $\sqrt{ }$ & $\sqrt{ }$ \\
\hline $\begin{array}{l}\text { Drawing } \\
\text { Manage } \\
\text { ment }\end{array}$ & $\sqrt{ }$ & & $\sqrt{ }$ & & & & & $\sqrt{ }$ & & & & & & & & & & & & & & & & & & & & & & & \\
\hline $\begin{array}{l}\text { Tender } \\
\text { Manage } \\
\text { ment }\end{array}$ & $\sqrt{ }$ & & $\sqrt{ }$ & $\sqrt{ }$ & & $\sqrt{ }$ & $\sqrt{ }$ & & $\sqrt{ }$ & $\sqrt{ }$ & & $\sqrt{ }$ & $\sqrt{ }$ & & $\sqrt{ }$ & & & & & & & & & $\sqrt{ }$ & $\sqrt{ }$ & & & & & & $\sqrt{ }$ \\
\hline $\begin{array}{l}\text { Change } \\
\text { Manage } \\
\text { ment }\end{array}$ & & & $\sqrt{ }$ & & & & & & & & & & & & & & & & $\sqrt{ }$ & $\sqrt{ }$ & & $\sqrt{ }$ & $\sqrt{ }$ & $\sqrt{ }$ & & & & $\sqrt{ }$ & $\sqrt{ }$ & & \\
\hline
\end{tabular}




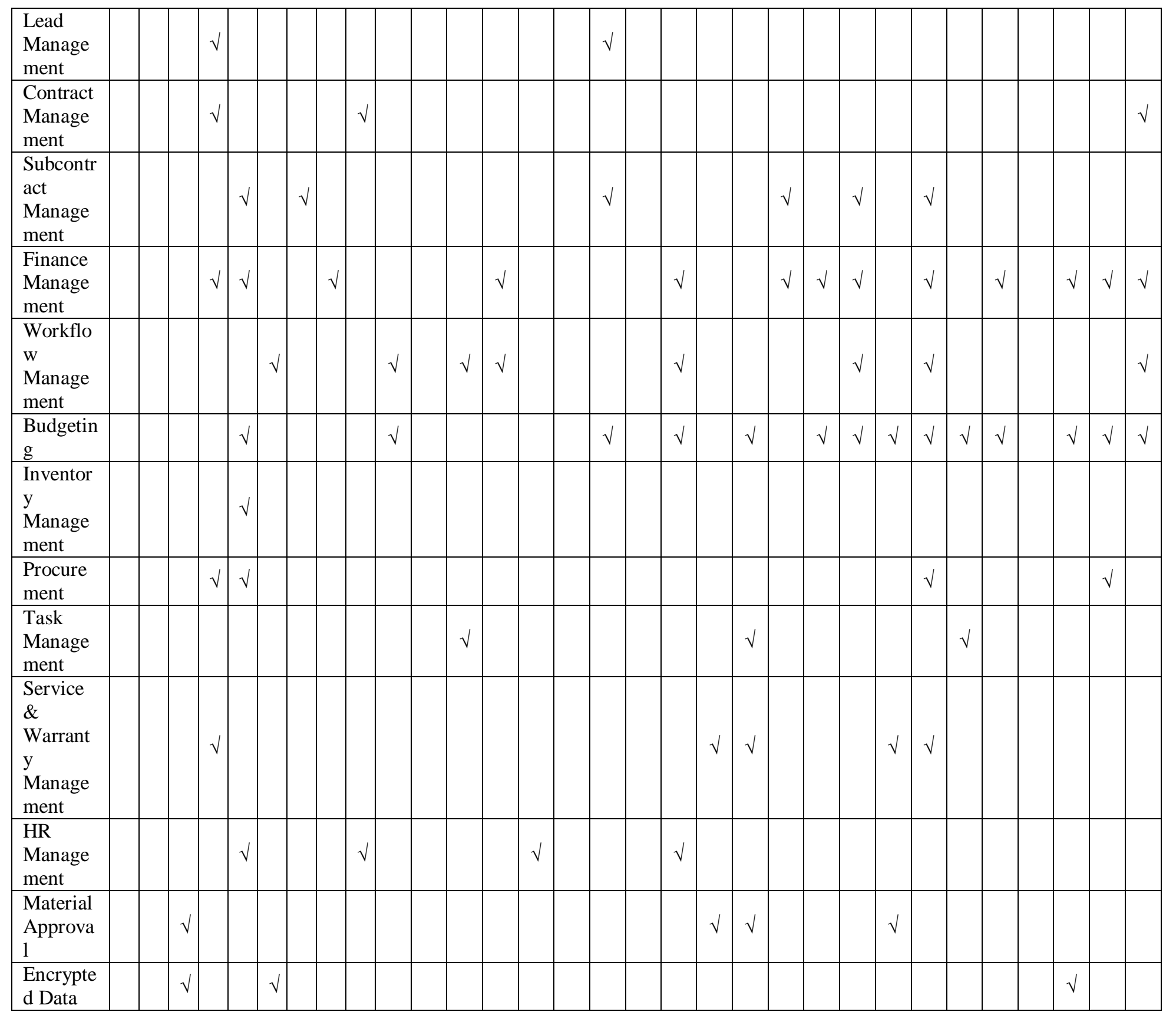




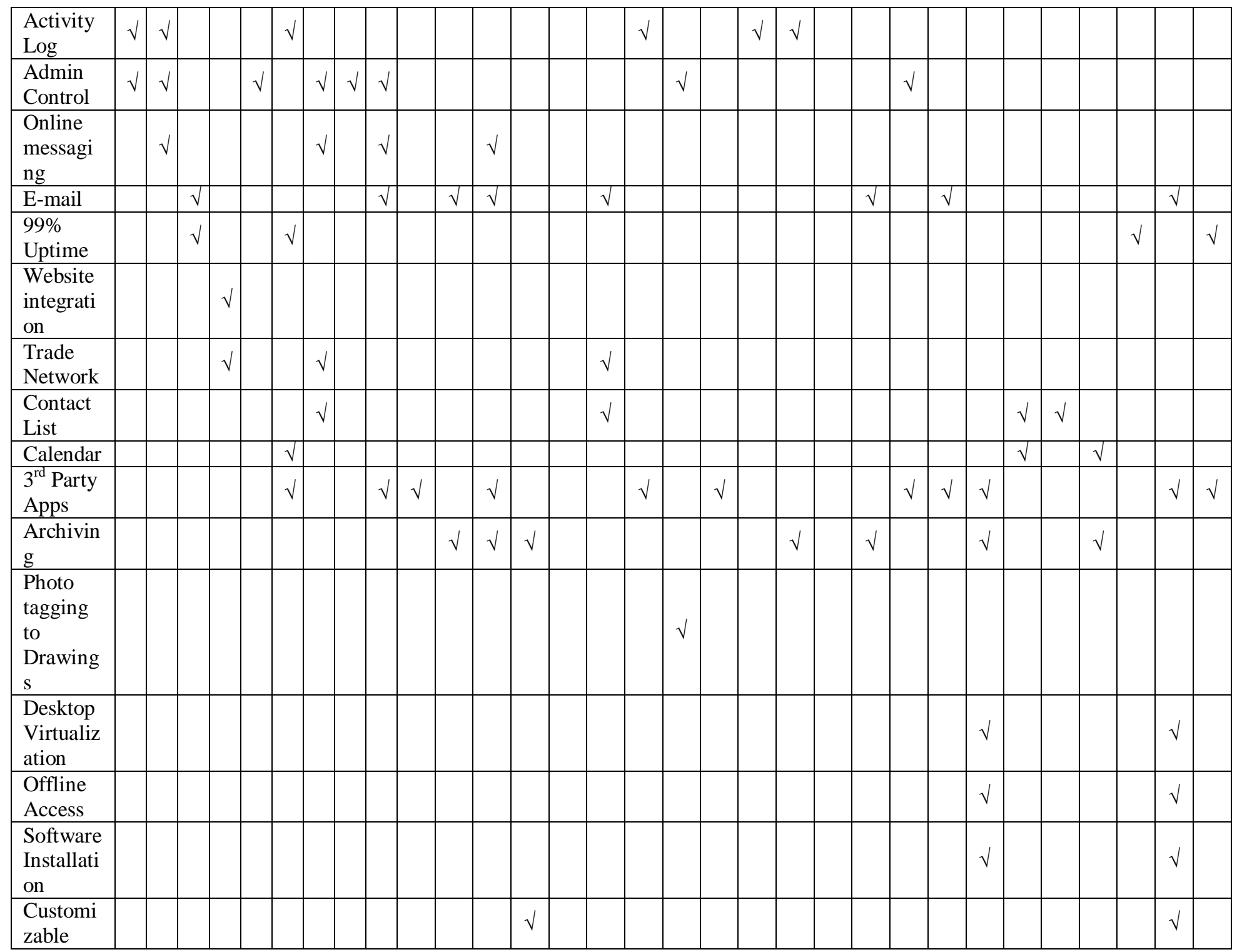




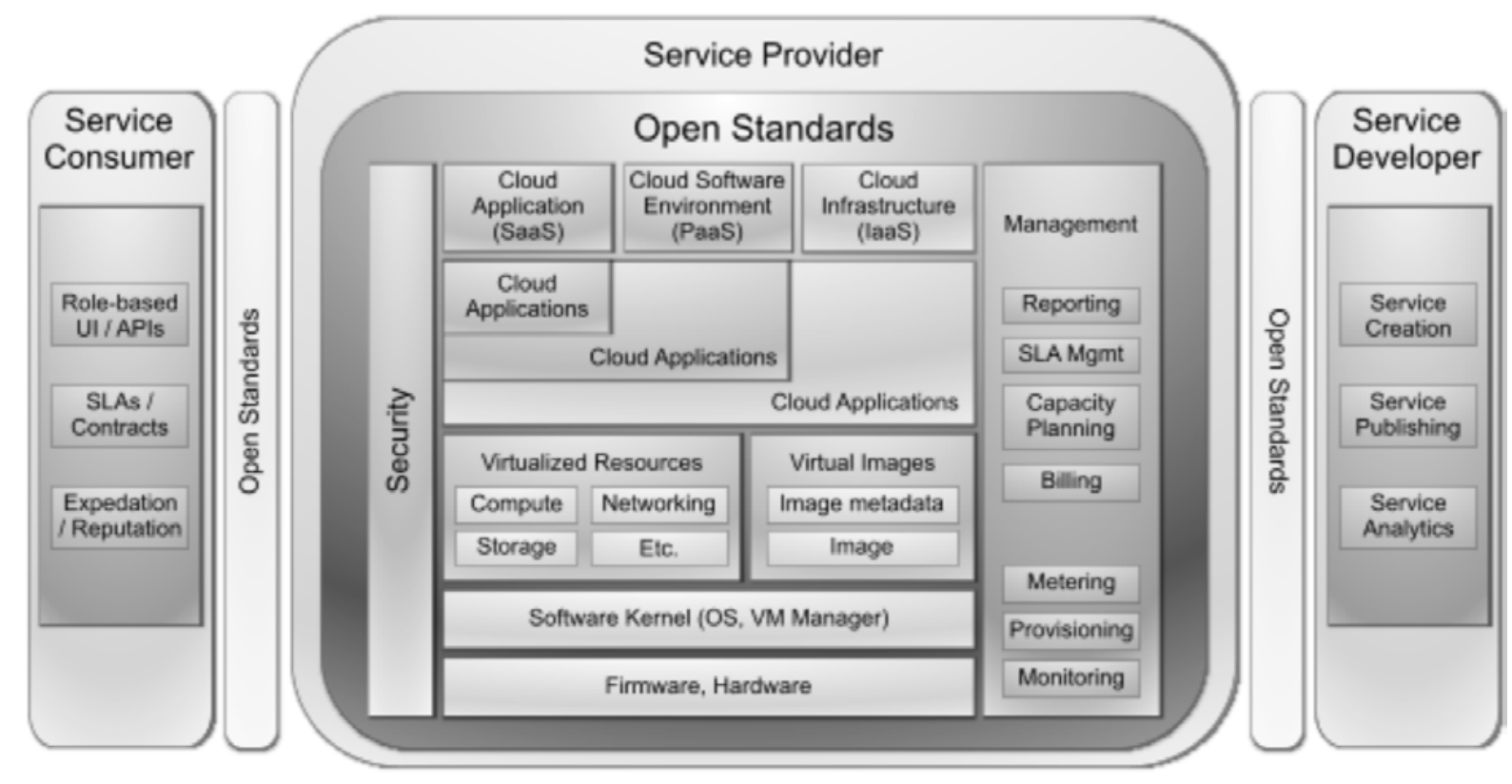

Figure 1: Taxonomy of Cloud Computing [9] 


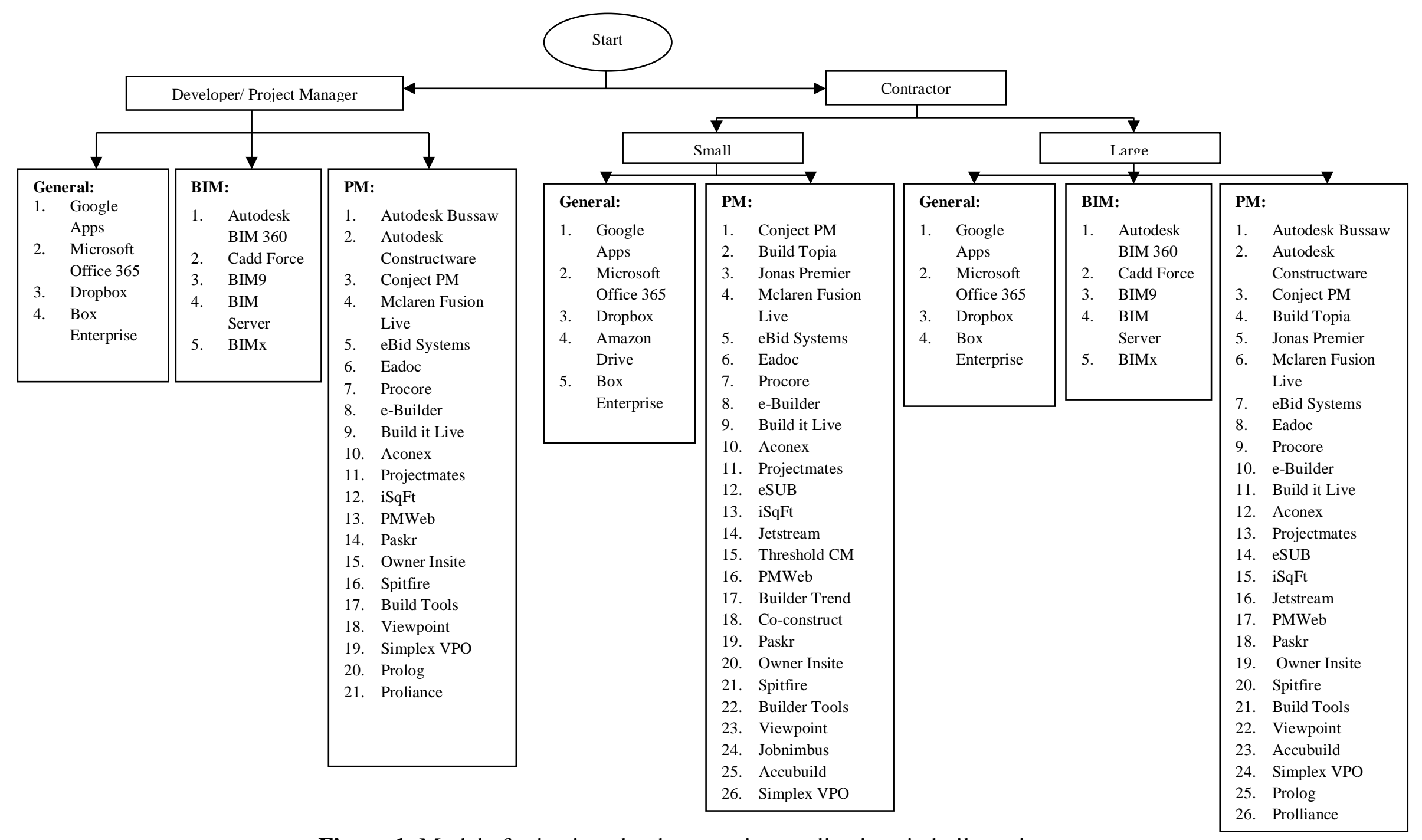

Figure 1. Model of selecting cloud computing applications in built environment 